\title{
INPLEMENTASI BUSINESS INTELLIGENCE DAN MARKET BASKET ANALYSIS UNTUK ANALISA DATA PENJULAN DI PT. ABC
}

\author{
${ }^{1)}$ I Putu Susila Handika, ${ }^{2)}$ I Gusti Agung Ayu Ari Satyawati \\ ${ }^{1)}$ Program Studi Teknik Informatika, STMIK STIKOM Indonesia \\ ${ }^{2}$ Program Studi Sistem Komputer, STMIK STIKOM Indonesia \\ ${ }^{1,2)}$ Jl. Tukad Pakerisan No. 97 Denpasar - Bali - Indonesia \\ E-mail : susila.handika@stiki-indonesia.ac.id,ayuari08@gmail.com
}

\begin{abstract}
ABSTRAK
Ditengah merebaknya kasus pandemi Covid-19 pada tahun 2020 di Indonesia, terjadi perubahan kecenderungan perilaku pelanggan dalam melakukan proses transaksi belanja khususnya pada gerai minimarket. Dengan diberlakukannya pysical distancing, pelanggan dituntut untuk berbelanja seefektif mungkin untuk menghindari penumpukan di dalam gerai. Manajemen perusahaan harus membuat setrategi untuk menyikapi perubahan perilaku dari pelanggan. Pada penelitian ini dikembangkan Business Intelligence dan metode Market Basket Analysis yaitu Apriori untuk menganalisa perilaku pelanggan dengan cara menganalisa riwayat transaksi penjualan. Hasil penelitian menunjukkan dashboard Business Intelligence dapat menampilkan data dalam bentuk grafik dan tabel sehingga memudahkan pengguna dalam proses analisa. Selain itu Association Rule menggunakan metode Apriori menghasilkan nilai support dan confidence sebagai gambaran produk-produk yang saling terkait, sehingga pihak merchendaising dapat dengan mudah membuat keputusan. Hasil pengujian blackbox menunjukkan aplikasi yang dikembangkan dapat diterima oleh pengguna karena semua kebutuhan pengguna dapat diselesaikan oleh aplikasi.
\end{abstract}

Kata Kunci: Sistem Informasi, Business Intelligence, Assosiation Rule, Apriori

\section{ABSTRACT}

In the midst of the outbreak of the Covid-19 pandemic in 2020 in Indonesia, there was a change in the tendency of customer behavior to process shopping transactions, especially at minimarket outlets. With the implementation of physical distancing, customers are required to shop as effectively as possible to avoid accumulation in outlets. Company management must make a strategy to respond to changes in customer behavior. In this study, Business Intelligence and Market Basket Analysis methods were developed, namely Apriori to analyze customer behavior by analyzing sales transaction history. The results show that the Business Intelligence dashboard can display data in the form of graphs and tables, making it easier for users in the analysis process. In addition, the Association Rule using the Apriori method produces support and confidence values as a description of interrelated products, so that merchandising parties can easily make decisions. The results of the blackbox test show that the application developed can be accepted by the user because all user needs can be completed by the application.

Keyword: Information System, Business Intelligence, Assosiation Rule, Apriori.

\section{PENDAHULUAN}

Seiring perkembangan zaman saat ini, kumunculan bisnis-bisnis sejenis kususnya bisnis minimarket juga semakin banyak. Kemunculan minimarket yang begitu banyak membuat manajemen perusahaan minimarket harus berfikir kreatif dan inovatif agar dapat bersaing dengan usaha sejenis dalam merebut pangsa pasar [1]. Kondisi persaingan yang ketat dengan usaha sejenis ini mengakibatkan para pengusaha retail tidak mampu bertahan untuk melawan para pesaingnya. Salah satu cara untuk merebut pangsa pasar adalah selalu menyediakan barang yang dibutuhkan oleh pembeli [2]. Apabila barang yang diharapkan oleh pelanggan dirasakan sesuai, maka dapat dikatakan kualitas pelayanan dari minimartket tersebut baik dan memuaskan [3].

Ditengah merebaknya kasus pandemi Covid-19 pada tahun 2020 di Indonesia, setiap individu diharuskan untuk melakukan pysical distancing atau pembatasan sosial secara fisik saat berada diruang publik. Adanya kondisi seperti ini, membuat perubahan kecenderungan perilaku pelanggan dalam melakukan proses transaksi belaja khususnya pada gerai minimarket. Para pelangan dituntut untuk melakukan transaksi belanja seefektif mungkin untuk menghindari penumpukan pelanggan. 
Dengan berubahnya perilaku pelanggan tersebut, manajemen perusahaan harus menyesuaikan setrategi bisnisnya selama pandemi ini.

Salah satu industri yang tedampak dengan perubahan perilaku pelanggan adalah PT. ABC. Sebagai salah satu industri yang bergerak dibidang retail, PT. ABC sudah memiliki gerai sebanyak 378 yang tersebar di Bali, Lombok, serta Makassar. PT. ABC sudah menggunakan sistem informasi serta datawarehouse untuk membantu proses bisnisnya. Salah satu upaya yang dapat dilakukan PT. ABC untuk menyikapi kondisi perubahan perilaku pelanggan adalah menganalisis data penjualan yang telah tersimpan. Oleh karena itu, diperlukan teknologi berupa Business Intelligence untuk mengolah data menjadi informasi yang berkualitas, ringkasan data, dan menghasilkan laporan yang baik sehingga diharapkan dapat melihat dan mengambil keputusan dengan cepat berdasarkan laporan yang dihasilkan [4], seperti penelitian yang dilakukan oleh Berlin Yap dan Yo Ceng Giap yang berjudul "Penerapan Business Intelligence Pada CV. Tanggamas Chemical Dengan Metode OLAP". Pada Penelitian tersebut Berlin dan Yo Ceng menyimpulkan jika penggunaan Business Intelligence dapat mengoptimalkan proses analisa data penjualan karena data penjualan dapat ditampilkan dalam bentuk grafik [5].

Selain itu, pengaturan layout produk pada toko juga memegang peranan penting untuk dapat membantu pelanggan dalam melakukan proses belanja yang efektif. Sering kali pelanggan memerlukan waktu yang cukup lama untuk menemukan barang yang sesuai dengan keinginannya. Hal tersebut dapat menyebabkan terjadinya loss opurtunity to sell akibat kesulitan mencari produk sedangkan bagi konsumen, hal tersebut akan menyebabkan ketidakpuasan berbelanja. Market Basket
Analysis dapat digunakan untuk membantu menganalisis pola belanja konsumen dengan memanfaatkan data transaksi penjualan sebelumnya [6]. Salah satu metode Market Basket Analysis yang paling banyak digunakan sampai saat ini adalah metode Apriori [7]. Apriori merupakan metode yang mencari Frequent item sets (kelompok setiap item) yang terdapat pada setiap data transaksi yang memenuhi syarat minimum support [8]. Pada penelitian yang dilakukan oleh Maulidiya dan Arif, metode apriori menghasilkan kecepatan yang lebih tinggi dibandingkan dengan metode Market Basket Analysis lainnya yaitu FPGrowth dengan parameter minimum support $=$ 0.06 dan confidence $=0.01$ [9].

\section{METODE}

\section{Kerangka Kerja Penelitian}

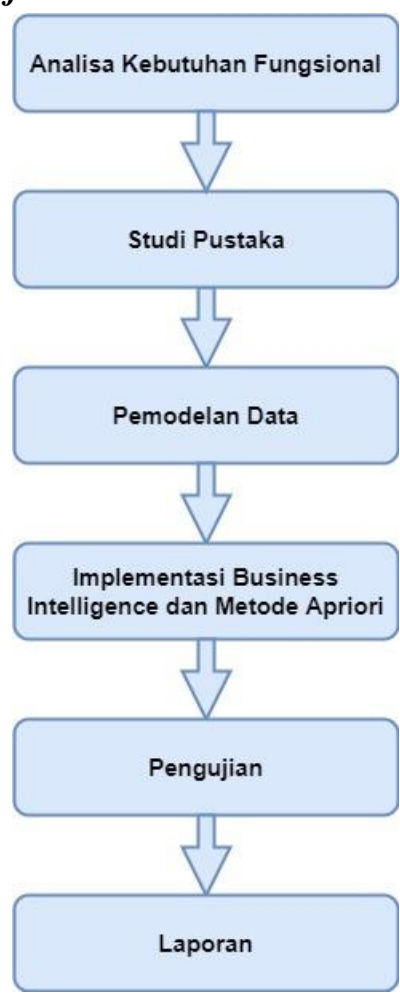

Gambar 1. Kerangkat Kerja Penelitian

Gambar 1 menunjukkan metode penelitian yang digunakan pada penelitian ini. Tahap analisa kebutuhan fungsional merupakan tahap untuk mengumpulkan kebutuhan informasi yang diperlukan pada PT. ABC. Selanjutnya 
dilakukan pemahaman kepustakaan terkait pengembangan Business Intelligence dan metode Market Basket Analysis yaitu Apriori. Tahap selanjutnya adalah pengumpulan data. Proses pengumpulan data dilakukan dengan observasi dan wawancara langsung dengan pihak terkait di PT. ABC. Setelah mendapatkan pemodelan data, tahap selanjutnya adalah mengimplementasikan Business Intelligence menggunakan metodologi dari Larrisa T.Moss, dimana metodologi tersebut terdiri dari 5 tahap [10]:

1. Justification, merupakan tahap untuk melakukan business case assesment.

2. Planing, merupakan tahap untuk menganalisa kebutuhan business intelligence agar dapat berjalan dengan baik. Kebutuhan yang dianalisa mulai dari kebutuhan infrastruktur dan kebutuhan project.

3. Business Analysis, yang terdiri dari data analysis, application prototyping, dan metadata repository analysis.

4. Desing, terdiri dari 3 kegiatan yaitu database design, ETL design, Metadata repository design.

5. Construction, terdiri dari tahapan yaitu, ETL Development, application development, data mining, metadata repository development.

Tahap terakhir adalah mengimplementasikan Market Basket Analysis menggunakan metode Apriori. Setelah didapat hasil dari penerapan Business Intelligence serta metode Apriori, tahap penelitian dilanjutkan ke pengujian sistem. Pengujian sistem dilakukan menggunakan metode black box

\section{HASIL}

\section{Analisa Kebutuhan}

Analisa kebutuhan fungsional bertujuan untuk mengetahui kebutuhan-kebutuhan yang diperlukan untuk membangun aplikasi Business
Intelligence dan Market Analysis untuk analisa data penjualan [11]. Adapun kebutuhan informasi yang ingin ditampilkan pada sistem adalah:

1. Sistem dapat menampilkan 10 SKU yang paling banyak dibeli.

2. Sistem dapat menampilkan 10 Store dengan penjualan terbanyak.

3. Sistem dapat menampilkan riwayat total penjualan pada bulan berjalan.

4. Sistem dapat menampilkan hasil market basket analisis.

5. Informasi yang ditampilkan pada dashboard dapat difilter berdasarkan SKU dan Store.

\section{Pemodelan Data}

PT. ABC telah memiliki datawarehouse sebagai tempat penyimpanan data yang digunakan untuk proses analisa. Pada tahap ini dilakukan pemodelan data yang telah tersimpan pada datawarehouse agar dapat memenuhi kebutuhan fungsional yang telah didapat pada proses sebelumnya. Skema datawarehouse yang telah dikembangkan sebelumnya ditunjukkan pada Gambar 2.

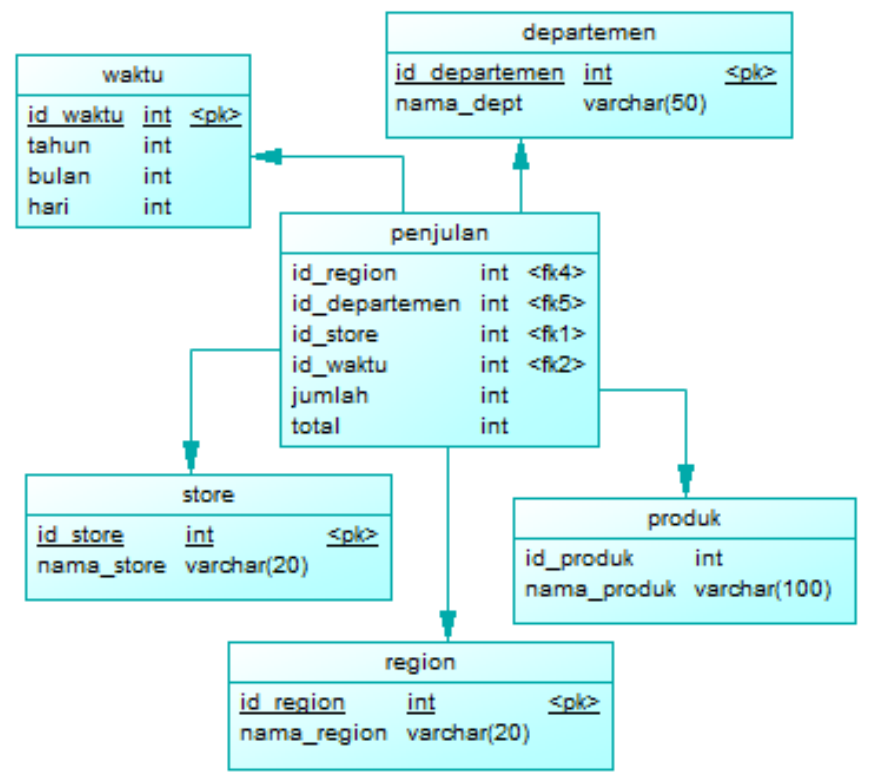

Gambar 2. Skema Datawarehouse Penjualan.

Dari skema datawarehouse yang telah ada, 
data yang digunakan pada pada penelitian ini adalah:

a. Data store untuk menunjukkan lokasi penjualan

b. Data Produk untuk menunjukkan produk yang terjual

c. Data waktu untuk menunjukkan periode penjualan

Data penjualan untuk melakukan kalkulasi summary dan kalkulasi metode apriori.

\section{Dashboard Business Intelligence}

Pengembangan aplikasi Business Intelligence, peneliti menggunakan bahasa pemrogramman PHP dengan framework laravel. Sedangkan proses perhitungan apriori, peneliti menggunakan bahasa pemrogramman python dengan framework flask. Hasil penelitian ini berupa dashboard berupa grafik dan tabel yang ditunjukkan pada Gambar 3 . Dalam dashboard tersebut, dapat dilihat grafik yang menunjukkan 10 SKU dengan penjualan terbanyak, 10 Store dengan penjualan paling banyak, riwayat total penjualan pada bulan berjalan serta hasil perhitungan association rule menggunakan metode apriori.

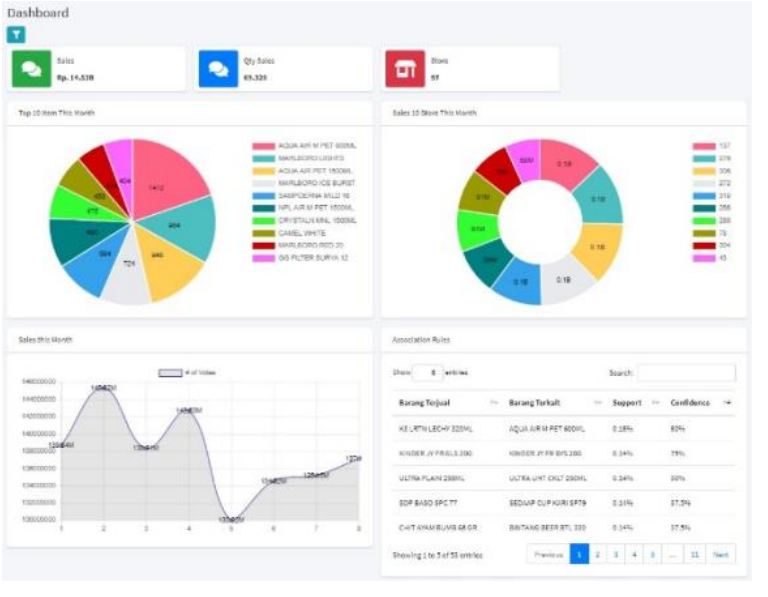

Gambar 3. Dashboard Business Intelligence.

Hasil perhitungan metode association rule menggunakan apriori dapat dilihat dengan jelas pada Gambar 4.

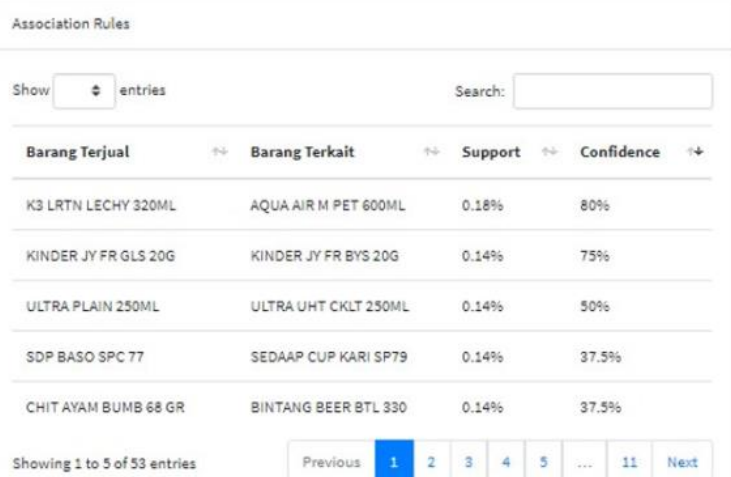

Gambar 4. Hasil Association Rule.

Pada Gambar 4, menunjukkan jika barang K3 LRTN LECHY 320ML akan terjual bersamaan dengan AQUA AIR 600ML dimana support dari hasil ini adalah $0.18 \%$ yang berarti kombinasi K3 LRTN LECHY 320ML dan AQUA AIR 600ML sebesar $0.18 \%$ dari total keseluruhan transaksi dan confidence adalah $80 \%$, berarti dari total transaksi K3 LRTN LECHY 320 ML terdapat AQUA AIR 600ML.

Dashboard dapat difilter berdasarkan SKU dan Store seperti yang ditunjukkan pada Gambar 5.

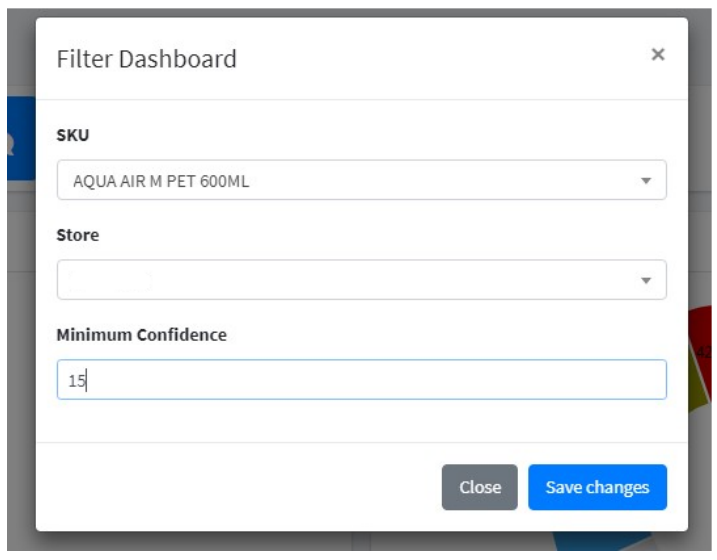

Gambar 5. Filter Dashboard.

Gambar 6 menunjukkan dashboard hasil filter data. Dimana nilai yang dimunculkan hanya untuk 1 SKU saja. 


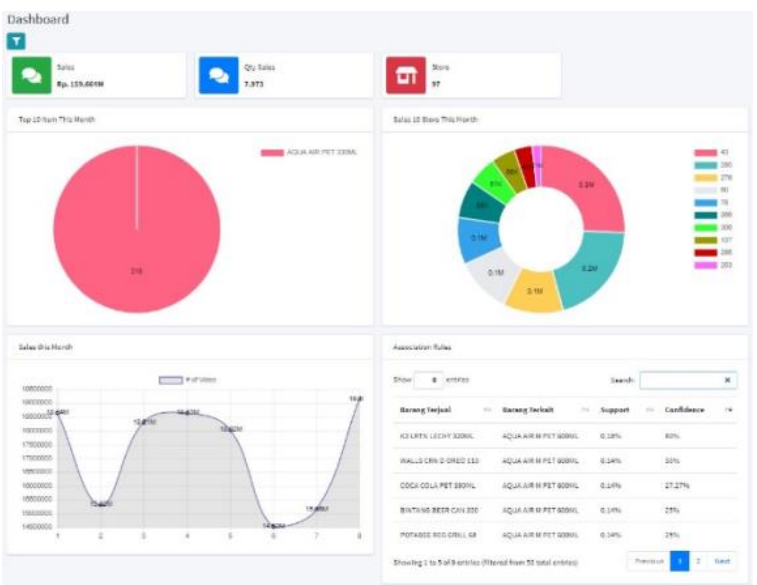

Gambar 6. Dashboard Hasil Filter.

\section{Pengujian}

Pada penelitian ini pengujian dilakukan menggunakan metode. Pengujian blackbox pada dasarnya didapat dari kebutuhan ketika proses perencanaan. Tujuan dari pengujian blackbox adalah melihat aplikasi yang telah dibuat apakh sesuai dengan kebutuhan dan fungsi yang diinginkan oleh pengguna[12]. Jika modul yang dijalankan diterima oleh user, maka diberikan status OK. Tabel 1 menunjukkan hasil pengujian fungsional blackbox.

Tabel 1. Hasil Pengujian Fungsional Blackbox.

\begin{tabular}{|c|c|c|}
\hline No & Kebutuhan & Status \\
\hline 1 & $\begin{array}{l}\text { Sistem dapat } \\
\text { menampilkan } 10 \mathrm{SKU} \\
\text { yang paling banyak dibeli }\end{array}$ & $\mathrm{OK}$ \\
\hline 2 & $\begin{array}{l}\text { Sistem dapat } \\
\text { menampilkan } 10 \text { Store } \\
\text { dengan penjualan } \\
\text { terbanyak }\end{array}$ & $\mathrm{OK}$ \\
\hline 3 & $\begin{array}{l}\text { Sistem dapat } \\
\text { menampilkan riwayat } \\
\text { total penjualan pada bulan } \\
\text { berjalan }\end{array}$ & $\mathrm{OK}$ \\
\hline 4 & $\begin{array}{l}\text { Sistem dapat } \\
\text { menampilkan hasil } \\
\text { market basket analisis }\end{array}$ & $\mathrm{OK}$ \\
\hline 5 & $\begin{array}{l}\text { Informasi yang } \\
\text { ditampilkan pada } \\
\text { dashboard dapat difilter } \\
\text { berdasarkan SKU dan }\end{array}$ & $\mathrm{OK}$ \\
\hline
\end{tabular}

\begin{tabular}{crc}
\hline No & Kebutuhan & Status \\
\hline \multicolumn{2}{c}{ Store } &
\end{tabular}

\section{KESIMPULAN}

Kesimpulan yang didapat dari hasil penelitian ini adalah:

1. Dengan adanya aplikasi Business Intelligence dan Market Basket Anlysis dapat membantu pihak Merchendaising untuk menganalisa produk-produk yang paling banyak terjual pada periode tertentu dan di toko tertentu.

2. Metode Apriori dapat menampilkan bagaimana keterkaitan produk lainnya dengan produk yang paling laku sehingga memudahkan pihak Merchendaising untuk membuat keputusan seperti tata letak suatu produk yang saling terkait.

3. Hasil pengujian Blackbox menunjukkan semua point kebutuhan dapat diterima oleh pengguna karena aplikasi yang dibuat dapat memenuhi semua kebutuhan sistem.

\section{DAFTAR PUSTAKA}

[1] A. Hijriani, E. Aprilliana, R. I. A. Pribadi, and D. Sakethi, "Business Intelligence Dashboard (BID) Pada Usaha Mikro Bidang Retail Studi Kasus CV Duta Square Bandar Lampung," Matrix J. Manaj. Teknol. dan Inform., vol. 10, no. 1, pp. 11-18, Mar. 2020.

[2] N. Sari and S. Setiyowati, "Pengaruh Keragaman Produk Dan Kualitas Pelayanan Terhadap Kepuasan Konsumen Di PB Swalayan Metro,” Jul. 2017.

[3] Zamroni, A. Widarko, and K. Abs, "eJurnal Riset Manajemen PRODI MANAJEMEN Pengaruh Harga, Lokasi dan Kualitas Layanan Terhadap Keputusan Pembelian pada Toko Komputer Cyber Mall Malang ( Studi Kasus Pada Konsumen Cyber Mall 
Malang)," Aug. 2020.

[4] Ikrimah and T. D. Purwanto, "Business Intellingence Pada Sistem Informasi Monitoring Transaksi Penjualan Daya Beli Konsumen," Bina Darma Conf. Comput. Sci., vol. 2, no. 1, pp. 9-21, 2020.

[5] B. Yap and Y. C. Giap, "PENERAPAN BUSINESS INTELLIGENCE PADA CV. TANGGAMAS CHEMICHAL DENGAN METODE OLAP," ALGOR, vol. 2, no. 1, pp. 57-65, Nov. 2020.

[6] F. Panjaitan, A. Surahman, and T. D. Rosmalasari, "Analisis Market Basket Dengan Algoritma Hash-Based Pada Transaksi Penjualan (Studi Kasus: TB. Menara)," J. Teknol. dan Sist. Inf., vol. 1, no. 2, pp. 111-119, 2020.

[7] dan Hadryan Eddy, "Analisa data transaksi penjualan barang menggunakan algoritme Apriori dan FPGrowth," Apr. 2020.

[8] N. Agustiani, D. Suhendro, W. Saputra, and S. Tunas Bangsa Pematangsiantar, "Penerapan Data Mining Metode Apriori Dalam Implementasi Penjualan Di Alfamart," Pros. Semin. Nas. Ris. Dan Inf. Sci., vol. 2, no. 0, pp. 300-304, Jul. 2020.

[9] H. Maulidiya and A. Jananto, "Asosiasi Data Mining Menggunakan Algoritma Apriori Dan Fpgrowth Sebagai Dasar Pertimbangan Penentuan Paket Sembako," Proceeding SENDI_U, 2020.

[10] S. Dian Purnamasari dan Alek Wijaya, S. Dian Purnamasari, A. Wijaya, U. Bina Darma Jalan Jenderal Ahmad Yani No, and P. Sur-el, "DASHBOARD SISTEM INFORMASI EKSEKUTIF PENJUALAN," J. Ilm. Matrik, vol. 19, no. 3, pp. 207-216, 2017.

[11] A. Priyatna, "Implementasi Sistem Penunjang Keputusan Menggunakan Business Intelligence Untuk UMKM Di Gunung Putri Kab. Bogor," J. Khatulistiwa Inform., vol. 7, no. 1, Jul. 2019.

[12] F. C. Ningrum, D. Suherman, S. Aryanti, H. A. Prasetya, and A. Saifudin, "Pengujian Black Box pada Aplikasi
Sistem Seleksi Sales Terbaik Menggunakan Teknik Equivalence Partitions," vol. 4, no. 4, 2019. 